\title{
A new paradigm evaluating cost per cure of HCV infection in the UK
}

\author{
Stephen T. Barclay ${ }^{1}$, Graham S. Cooke², Elizabeth Holtham³ ${ }^{3}$ Aline Gauthier ${ }^{4}$, Jeremie Schwarzbard ${ }^{4}$, \\ Petar Atanasov ${ }^{4}$, William L. Irving ${ }^{3,5^{*}}$ and On behalf of HCV Research UK
}

\begin{abstract}
Background: New interferon (IFN)-free treatments for hepatitis $C$ are more effective, safer but more expensive than current IFN-based therapies. Comparative data of these, versus current first generation protease inhibitors (PI) with regard to costs and treatment outcomes are needed. We investigated the real-world effectiveness, safety and cost per cure of 1st generation PI-based therapies in the UK.

Methods: Medical records review of patients within the HCV Research UK database. Patients had received treatment with telaprevir or boceprevir and pegylated interferon and ribavirin (PR). Data on treatment outcome, healthcare utilisation and adverse events (AEs) requiring intervention were collected and analysed overall and by subgroups. Costs of visits, tests, therapies, adverse events and hospitalisations were estimated at the patient level. Total cost per cure was calculated as total median cost divided by SVR rate.

Results: 154 patients from 35 centres were analysed. Overall median total cost per cure was $£ 44,852$ (subgroup range, $£ 35,492$ to $£ 107,288)$. Total treatment costs were accounted for by PI: $68.3 \%$, PR: $26.3 \%$, AE management: $5.4 \%$. Overall SVR was $62.3 \%$ (range $25 \%$ to $86.2 \%$ ). $36 \%$ of patients experienced treatment-related AEs requiring intervention, $10 \%$ required treatment-related hospitalisation.

Conclusions: This is the first UK multicentre study of outcomes and costs of PI-based HCV treatments in clinical practice. There was substantial variation in total cost per cure among patient subgroups and high rates of treatment-related discontinuations, AEs and hospitalisations. Real world safety, effectiveness and total cost per cure for the new IFN free combinations should be compared against this baseline.
\end{abstract}

Keywords: Hepatitis C, Protease inhibitors, Cost, SVR

\section{Background}

Hepatitis $\mathrm{C}$ virus (HCV) infection remains a global public health issue with most recent estimates suggesting that more than 180 million people have been infected worldwide [1]. The combination of peginterferon alfa (IFN), ribavirin (RBV) and one of the first generation protease inhibitors (PI), boceprevir (BOC) or telaprevir (TVR) was the standard care for genotype $1 \mathrm{HCV}$ up to $2014[2,3]$.

IFN based HCV treatment is able to cure HCV (as defined by sustained virological response, SVR) [2] which is associated with improved clinical outcomes [4-6].

\footnotetext{
* Correspondence: will.irving@nottingham.ac.uk

${ }^{3} \mathrm{NIHR}$ Nottingham Digestive Diseases Biomedical Research Unit, University of Nottingham, Nottingham, UK

${ }^{5}$ Microbiology, Queen's Medical Centre, Nottingham NG7 2UH, UK

Full list of author information is available at the end of the article
}

However, common adverse events (AEs) associated with traditional $1^{\text {st }}$ generation PI-based therapies include skin rashes, pruritus, anaemia, neutropaenia, nausea and dysgeusia [7]. In addition, treatment with IFN may cause psychiatric adverse events such as depression [8]. Evidence suggests that treatment-related AEs have a negative impact on health-related quality of life (HRQoL) leading to higher rates of premature discontinuation and lower SVR rates than reported from clinical trials $[9,10]$. Evidence from clinical trials suggests that in treatment naïve genotype 1 patients, triple therapy of $\mathrm{PR}+1^{\text {st }}$ generation PIs results in SVR rates of between 65-75 \% [11-14] however, lower effectiveness has been reported in real-world studies (44-55\%) [15-18]. 
The treatment landscape of $\mathrm{HCV}$ is changing rapidly with the emergence of novel highly effective all oral combination therapies active against genotype 1 [2]. With better efficacy, improved safety and substantially shortened treatment durations, these IFN - and RBVfree treatments are expected to become the cornerstone of HCV therapy, [19-23]; these advances represent a major treatment improvement for patients. However, current pricing, combined with the likely increased patient demand, means these regimens pose a significant budgetary impact in developed healthcare systems [24]. Recently, the concept of "cost per SVR" has evolved to take account of opportunity costs (i.e. the loss of potential gain from other alternatives when one alternative is chosen) in HCV management. More data is required to understand the total cost per SVR of existing IFN-based therapies to allow meaningful comparison with newer interferon free regimens.

To date there have been no published real-world studies assessing the cost per cure, safety and effectiveness of $\mathrm{PR}+1^{\text {st }}$ generation PI triple therapy in the UK. This study aimed to estimate the total cost per $\mathrm{HCV}$ patient cured associated with first generation PI-based therapy in a real world setting, across a large number of centres. As secondary objectives, this study also aimed at estimating the effectiveness, safety and tolerability of these regimens.

\section{Methods}

\section{Study design and patients}

This was a retrospective observational multi-centre study of patients enrolled in the HCV Research UK biobank, who received a first generation PI-based regimen between July 2012 and July 2014 through National Health Service (NHS) hospitals following recommendation by the National Institute for Health and Care Excellence (NICE) $[25,26]$ and the Scottish Medicines Consortium. HCV Research UK is a cohort of 10,000 patients, plus database and biorepository, enrolled with informed consent from 59 centres across England, Scotland and Wales [27]. Patients within HCV Research UK were considered eligible for this analysis if they were 18 years of age or older, had HCV genotype 1 infection and had received either TVR or BOC in association with PEG + RBV with a known treatment outcome. Patients were randomly selected for this study from all eligible patients using a number generator. A TVR: BOC sample ratio of 2:1 was chosen to reflect use in clinical practice among the HCV Research UK cohort.

\section{Data collection}

Baseline data available from within the HCV Research UK database were supplemented by a detailed clinic case note review. Data collected included patient characteristics at initiation of the PI-based treatment (age, gender, ethnicity, liver disease status, genotype, blood test results, comorbidities recorded in the HCV Research UK database relating to renal failure, diabetes, HIV co-infection, depression, haemophilia and cancer (other than HCC)), previous $\mathrm{HCV}$ therapy (type of treatment and associated response), details regarding the PI-based therapy, treatment outcome, safety and healthcare resource use (nurse and physician visits, tests and investigations, medications used to treat AEs, and hospitalisations). Details on comorbidities at baseline were gathered through a review of the patient's clinical notes as well as patient questionnaire. IL28B genotyping at locus rs12979860 was performed (by Micropathology Ltd, Coventry, UK) post-hoc using a Roche Hybprobe kit and meltcurve analysis.

\section{Assessment of outcomes}

The outcomes of interest included SVR, which was assessed at 12 or 24 weeks. The incidence and type of adverse events (AEs) requiring therapeutic intervention, healthcare resource use, treatment discontinuation and/ or hospitalisation was collected by the study centre through a standardised questionnaire and quality controlled by a study coordinator. The relationship of HCV therapy to each $\mathrm{AE}$ was assessed independently by two physicians (STB, GSC), and categorised as "likely", "unlikely" or "can't tell". Any discrepancy between assessments was resolved by discussion. In total, there were 12 discrepancies after the initial individual assessments, all of which were agreed on after discussion with no further action needed.

Costs were estimated from the NHS perspective. The unit costs to be applied were derived from the British National Formulary for drugs [28]. The cost of managing $\mathrm{HCV}$ was estimated by applying the national unit costs to the number of physician and nurse visits, medications and tests [29]. The cost of hospitalisations was estimated based on Health Resource Group (HRG) codes classifying the reasons for hospitalisation and procedures undertaken during the stay [30]. Corresponding unit costs were obtained from the NHS reference costs [31]. Total costs were estimated and cost per cure was calculated as total median cost divided by SVR rate. For the conversion of UK pound ( $£$ ) to US dollar (\$), the Bank of England exchange rate was applied $(£ 1=\$ 1.4905)$ [32].

\section{Statistical analysis}

Sample size was not formally assessed and the number of patients enrolled was based on time and resource constraints. Descriptive statistics were analysed according to treatment status (naïve vs experienced) and liver disease status (cirrhosis vs no cirrhosis) at baseline. The proportion of patients achieving SVR was determined 
overall, by treatment (BOC vs TVR) and by liver disease status. The calculation of SVR took into account all patients, including those who discontinued therapy prematurely. The statistical significance was tested for each comparison using a Chi-square test.

Logistic regression was conducted to assess the impact of patient characteristics on the probability of reaching SVR. The list of covariates was specified a priori and included age, liver disease status, gender, treatment naïve vs experienced, HIV co-infection, IL28B subtypes, history of depression, diabetes, genotype and race. A stepwise procedure was run to identify the most significant covariates.

The incidence of AEs and of AEs assessed as "likely" to be related to $\mathrm{HCV}$ treatment was estimated overall and by type of AE. The incidence of AEs leading to treatment discontinuation and/or to hospitalisation was also estimated.

To identify factors which have an impact on the probability of experiencing an $\mathrm{AE}$, a logistic regression was conducted. The list of covariates included age, gender, treatment regimen, past treatment history, liver disease status, HIV status, history of depression and diabetes.

Sensitivity analyses were performed to assess the impact of PI drug price discounts of $30 \%, 40 \%$ and $50 \%$ and the impact of including management costs of 'can't tell' AEs on the total cost per cure.

\section{Results}

\section{Baseline characteristics}

From the initial 160 patients selected for this study from the HCV Research UK database, 8 patients did not in fact start TVR/BOC therapy, 3 patients were switched from one PI to the other, 1 patient had a genotype 3 infection, and for 5 patients, the clinics concerned notified us that they would not be able to retrieve and return the data within our specified timeframe, resulting in a total of 17 patients being excluded. An additional 11 patients were randomly selected, resulting in a total of 154 patients entered into this study derived from 35 centres.

Table 1 shows the baseline characteristics of all patients enrolled in this study. Of all patients, 63/154 (40.9\%) had at least one comorbidity and 8/154 (5.2\%) had at least two. The most common comorbidities at baseline were reported history of depression (40/154, $26 \%)$, HIV co-infection (10/154, $6.5 \%)$, diabetes (8/154, $5.2 \%)$, haemophilia $(8 / 154,5.2 \%)$, cancer $(6 / 154,3.9 \%)$ and renal failure $(1 / 154,0.7 \%)$. Over half the patients were treatment experienced $(80 / 154,52 \%)$, the majority having been treated with PEG + RBV (62/80, $77.5 \%$ ). The nature of the previous treatment regimen was not available for the other 18 patients. Among treatmentexperienced patients, 35/80 (43.7\%) were relapsers and $36 / 80(45.0 \%)$ were non-responders. This information was not available for 9 patients.
Table 1 Baseline characteristics for total cohort

\begin{tabular}{|c|c|}
\hline & All patients $(n=154)$ \\
\hline Age [Mean, (SD)] & $49.6(9.01)$ \\
\hline \multicolumn{2}{|l|}{ Gender } \\
\hline Male [\%] & $73.4 \%$ \\
\hline Female [\%] & $26.6 \%$ \\
\hline \multicolumn{2}{|l|}{ Ethnicity } \\
\hline White [\%] & $94.2 \%$ \\
\hline \multicolumn{2}{|l|}{ Liver disease (Metavir stage) } \\
\hline Non-cirrhotic (F0-F3) [\%] & $78.6 \%$ \\
\hline Cirrhotic (F4 including 1 HCC) [\%] & $21.4 \%$ \\
\hline \multicolumn{2}{|l|}{ Treatment history } \\
\hline Experienced [\%] & $52.0 \%$ \\
\hline Naïve [\%] & $48.0 \%$ \\
\hline \multicolumn{2}{|l|}{ Response to previous therapy } \\
\hline Relapse [\%] & $43.7 \%$ \\
\hline No response [\%] & $45.0 \%$ \\
\hline Missing [\%] & $11.3 \%$ \\
\hline \multicolumn{2}{|l|}{ HCV genotype } \\
\hline Genotype 1a [\%] & $51.3 \%$ \\
\hline Genotype 1b [\%] & $18.8 \%$ \\
\hline G1 subtype Missing [\%] & $29.9 \%$ \\
\hline \multicolumn{2}{|l|}{ HCV therapy } \\
\hline Telaprevir treatment [\%] & $69.1 \%$ \\
\hline Boceprevir treatment [\%] & $33.1 \%$ \\
\hline \multicolumn{2}{|l|}{ IL28B status (SNP rs12979860) } \\
\hline Heterozygous CT [\%] & $56.9 \%$ \\
\hline Homozygous CC [\%] & $29.4 \%$ \\
\hline Homozygous TT [\%] & $13.7 \%$ \\
\hline Missing [\%] & $0.7 \%$ \\
\hline \multicolumn{2}{|l|}{ Comorbidities } \\
\hline Depression [\%] & $26.0 \%$ \\
\hline HIV co-infection [\%] & $6.5 \%$ \\
\hline Diabetes [\%] & $5.2 \%$ \\
\hline Haemophilia [\%] & $5.2 \%$ \\
\hline Cancer [\%] & $3.9 \%$ \\
\hline Renal failure [\%] & $0.7 \%$ \\
\hline
\end{tabular}

More treatment-experienced patients had cirrhosis compared to treatment-naïve $(24 / 80(30.0 \%)$ vs $9 / 74$ $(12.2 \%) ; p=0.007)$. Patients with cirrhosis were significantly older than those with milder liver disease (stages F0 - F3) (55.6 years (SD: 7.16) vs 48.1 years (SD: 8.9); $p<0.0001)$.

\section{Effectiveness results}

Overall 96/154 (62.3\%) patients achieved SVR. SVR rate in patients treated with BOC was $63.1 \%(65 / 103)$ and 
$60.8 \%(31 / 51)$ in patients treated with TVR $(p=0.89)$. The SVR rate among patients who were treatment-naïe was $51 / 74$ (68.9 \%) compared to $12 / 36$ prior non- responders (33.3\%; $p=0.004$, Table 2). Patients with cirrhosis showed consistently lower SVR compared to those with milder liver disease regardless of previous treatment status. The logistic regression found age, cirrhotic status and IL28b genotype to be significant predictors of SVR (Table 3). Patients with cirrhosis were almost 3 times less likely to achieve SVR compared to those with milder liver disease (F0 - F3) $(\mathrm{OR}=0.35$; 95 \%CI: 0.13, 0.94). Patients with a CC genotype of IL28b were around 9 times more likely to achieve SVR than those with non-CC genotype $(\mathrm{OR}=0.116$; $95 \% \mathrm{CI}$ : $0.037,0.365)$.

\section{Safety analysis}

Over the study period 70/154 (45 \%) of the study population experienced at least one $\mathrm{AE}$ requiring intervention. The total number of AEs requiring intervention was 178 (see Additional file 1 for details). 141/178 (79.2 \%) of these were assessed as "likely" to be related to treatment. Twenty-two of the 178 (12.4\%) AEs requiring intervention were due to anaemia. This was managed by ribavirin dose reduction (16/22, $72.7 \%$ ), treatment with erythropoietin analogues (6/22, $27.3 \%)$ and/or blood transfusion $(15 / 22,68.2 \%)$. All the patients who required intervention for neutropaenia, $(n=6)$ were treated with GCSF, and the single case of thrombocytopenia $(n=1)$ was managed with a dose reduction.

Fifty-five out of 154 (33\%) patients stopped therapy prematurely - of those 17/55 (30.9\%) because of adverse events, 24/55 (43.6\%) patients failed stopping rules, 12/55 (21.8) patients withdrew themselves from therapy, and for $2 / 55$ (3.6 \%) patients the physician withdrew therapy. There were 36 hospitalisations amongst 29 patients and, of those, 16 (44.4\%) hospitalisations were classified as "likely" to be treatment related, comprising of 15 hospitalisations due to anaemia (all were associated with blood transfusion) and 1 due to severe headache (see Supplementary material).
Using logistic regression, liver disease status, treatment regimen, gender and past treatment experience were statistically significant predictors of the incidence of any AE (see Supporting material). Cirrhotic patients had a 3 -fold increased risk of experiencing an AE compared with patients with no cirrhosis $(p=0.0206)$. Patients on TVR were twice as likely to experience an AE compared to patients on BOC $(p=0.0445)$. Females had approximately a 2-fold increased risk of AEs compared to males $(p=0.0384)$ as did treatment-naïve patients compared to experienced patients $(p=0.0476)$.

\section{Economic assessment}

The overall median total cost per HCV cure was $£ 44,852$ $(\$ 66,852)$. Median cost per HCV cure varied according to prior treatment status: $£ 83,948(\$ 125,125)$ for previous non-responders, $£ 39,150(\$ 58,353)$ for prior relapsers and $£ 37,958(\$ 56,576)$ for treatment naïve patients (Table 4).

Patients with cirrhosis consistently showed higher costs per cure compared to those with milder liver disease across subgroups - $£ 61,496(\$ 91,660)$ vs $£ 35,492$ $(\$ 52,900)$ in treatment naïve patients; $£ 49,016(\$ 73,058)$ vs $£ 37,455(\$ 55,827)$ in prior relapsers; $£ 107,288$ $(\$ 159,913)$ vs $£ 73,098(\$ 108,953)$ in non-responders.

Using NHS list prices for the base case analysis total direct cost associated with the management of the $154 \mathrm{HCV}$ patients was estimated to be $£ 4,289,909(\$ 6,394,109)$. The total drug costs for the 154 patients associated with PI therapies accounted for $68.3 \%$ of total cost $(£ 2,930,769$; $\$ 4,368,311)$, PEG accounted for $19.5 \%$ ( $£ 834,485$; $\$ 1,243,800)$ and RBV, $6.8 \%(£ 290,975 ; \$ 433,698)$ (Table 5). In the base case analysis, 'other' costs accounted for $5.4 \%$ of total costs ( $£ 233,780 ; \$ 348,449)$, comprising of consultant/nurses visits $(59.9 \%$; $£ 139,992)$; tests $(22.5 \%$; $£ 52,616$ ); medications for adverse events (including blood transfusions) ( $7.4 \% ; £ 17,233)$; other investigations $(6.3 \%$; $£ 14,576)$ and hospitalisations (3.9\%; £9,209) (Table 5). Management of depression accounted for a small fraction of these costs.

All but 1 (13/14) patient experiencing a 'likely' treatment-related hospitalisation had a single hospital

Table 2 SVR rate by regimen, cirrhosis status and prior treatment history

\begin{tabular}{llll}
\hline Total $\left(n=145^{\mathbf{a}}\right)$ & Treatment-naïve patients $(n=74)$ & Prior relapsers $(n=35)$ & Prior non-responders $(n=36)$ \\
\hline $\begin{array}{l}\text { SVR rate } \\
\text { By regimen }\end{array}$ & $68.9 \%[57.1 ; 79.2]$ & $82.9 \%[66.4 ; 93.4]$ & $33.3 \%[18.6 ; 51.0]$ \\
$\quad$ BOC triple therapy $(n=48)$ & $66.7 \%[47.2 ; 82.7](n=30)$ & $75.0 \%[34.9 ; 96.8](n=8)$ & $30.0 \%[6.7 ; 65.2](n=10)$ \\
$\quad$ TVR triple therapy $(n=97)$ & $70.4 \%[54.8 ; 83.2](n=44)$ & $85.2 \%[66.3 ; 95.8](n=27)$ & $34.6 \%[17.2 ; 55.7](n=26)$ \\
By liver disease stage & & & \\
$\quad$ No-cirrhosis $(n=114)$ & $73.8 \%[61.5 ; 84.0](n=65)$ & $86.2 \%[68.3 ; 96.1](n=29)$ & $40.0 \%[19.1 ; 64.0](n=20)$ \\
$\quad$ Cirrhosis or HCC $(n=31)$ & $33.3 \%[7.5 ; 70.1](n=9)$ & $66.7 \%[22.3 ; 95.7](n=6)$ & $25.0 \%[7.3 ; 52.4](n=16)$ \\
\hline
\end{tabular}

a Previous treatment outcome status was not available for 9 patients 
Table 3 Logistic regression: Probability of achieving SVR

\begin{tabular}{|c|c|c|c|c|c|}
\hline \multirow{2}{*}{$\begin{array}{l}\text { Parameter } \\
\text { Age }\end{array}$} & \multirow{2}{*}{$\frac{\mathrm{OR}}{0.94}$} & \multicolumn{2}{|c|}{$95 \%$ Wald Confidence Limits } & \multirow{2}{*}{$\begin{array}{l}\text { Standard Error } \\
0.03\end{array}$} & \multirow{2}{*}{$\frac{P \text { value }}{0.02}$} \\
\hline & & 0.90 & 0.99 & & \\
\hline Gender & 1.20 & 0.49 & 2.93 & 0.23 & 0.69 \\
\hline \multicolumn{6}{|l|}{ Female (vs male) } \\
\hline Liver disease & 0.35 & 0.13 & 0.94 & 0.25 & 0.04 \\
\hline \multicolumn{6}{|l|}{ Cirrhosis (vs no cirrhosis) } \\
\hline Treatment status & 0.84 & 0.35 & 1.99 & 0.22 & 0.69 \\
\hline \multicolumn{6}{|l|}{ Experienced (vs naïve) } \\
\hline HIV co-infection $(n=10)$ & 2.56 & 0.44 & 14.77 & 0.45 & 0.29 \\
\hline \multicolumn{6}{|l|}{ Absence (vs presence) } \\
\hline Depression $(n=40)$ & 0.88 & 0.35 & 2.22 & 0.24 & 0.79 \\
\hline \multicolumn{6}{|l|}{ Absence (vs presence) } \\
\hline Diabetes $(n=8)$ & 4.94 & 0.62 & 39.56 & 0.53 & 0.13 \\
\hline \multicolumn{6}{|l|}{ Absence (vs presence) } \\
\hline IL28b & 0.12 & 0.04 & 0.37 & 0.29 & 0.0002 \\
\hline \multicolumn{6}{|l|}{ Non-CC (vs CC) } \\
\hline Genotype & 1.09 & 0.37 & 3.22 & 0.29 & 0.28 \\
\hline \multicolumn{6}{|l|}{ G1a (vs G1b) } \\
\hline Race & 0.31 & 0.04 & 2.42 & 0.52 & 0.27 \\
\hline Other (vs white) & & & & & \\
\hline
\end{tabular}

episode with 1 patient being admitted twice. The mean number of hospital days spent per hospitalisation was 3.5 .

In the UK, treatment is generally supervised by a clinical nurse specialist, however 78/154 (51 \%) of patients had at least one consultant (hepatology or infectious diseases) visit and 17/154 (11 \%) patients required at least one dermatologist visit during treatment. The mean number of consultant visits per patient during the follow-up was 1.2, with a mean number of nurse visits of 14.5. During the follow-up period, patients had, on average, 13 liver function tests, 10 electrolyte tests and 5 $\mathrm{HCV}$ viral load tests. In total 'other healthcare costs' accounted for approximately $£ 1,500$ per patient; $£ 232,573$ per 154 patients.

The PI price sensitivity analysis (30\%, $40 \%, 50 \%$ discount) indicated that a $10 \%$ drop in PI drug price was associated with a decrease of $7 \%$ in the cost per cure
(Table 5). Discount rates sensitivity analyses stratified according to outcome of previous therapy as well as liver disease status showed clearly that no response to previous therapy as well as the presence of cirrhosis is associated with increases in total costs per cure (see Supporting material).

In the base case analysis, only 'likely' hospitalisations and AEs were included. 141 AEs were deemed 'likely' and 24 'can't tell' (the remaining 13 being deemed "unlikely"). The impact of inclusion of cost for 'can't tell' classified AEs in the sensitivity analysis had only a negligible impact on total median cost per SVR - £38,027 vs $£ 37,958$ with and without respectively.

\section{Discussion}

The fact that HCV infection will incur a significant future healthcare burden is now commonly accepted. Use of highly effective therapies has been proven to improve

Table 4 Cost per HCV cure - by prior treatment and cirrhotic status

\begin{tabular}{|c|c|c|c|c|}
\hline Total $(n=154)$ & $\begin{array}{l}\text { Treatment naïve patients } \\
(n=74)\end{array}$ & $\begin{array}{l}\text { Prior relapsers } \\
(n=35)\end{array}$ & $\begin{array}{l}\text { Prior non-responders } \\
(n=36)\end{array}$ & $\begin{array}{l}\text { Prior treatment status unknown } \\
(n=9)\end{array}$ \\
\hline Overall & $£ 37,958$ & $£ 39,150$ & $£ 83,948$ & $£ 61,804$ \\
\hline \multicolumn{5}{|l|}{ By liver disease stage } \\
\hline Non cirrhotic $(n=114)$ & $£ 35,492$ & $£ 37,455$ & $£ 73,098$ & $£ 49,070$ \\
\hline Cirrhotic $(n=31)$ & $£ 61,496$ & $£ 49,016$ & $£ 107,288$ & NA \\
\hline
\end{tabular}


Table 5 Total costs

\begin{tabular}{|c|c|c|c|c|c|c|c|c|}
\hline Costs & $\begin{array}{l}\text { Base case Total cost } \\
\text { (in } £ \text { ) }\end{array}$ & $\%$ & $30 \%$ discount on $\mathrm{PI}$ & $\%$ & $40 \%$ discount on PI & $\%$ & $50 \%$ discount on $\mathrm{PI}$ & $\%$ \\
\hline Pls & $2,930,769$ & 68.3 & $2,051,538$ & 60.2 & $1,758,461$ & 56.4 & $1,465,385$ & 51.9 \\
\hline PegINF & 834,485 & 19.5 & 834,485 & 24.5 & 834,485 & 26.8 & 834,485 & 29.6 \\
\hline Ribavirin & 290,975 & 6.8 & 290,975 & 8.5 & 290,975 & 9.3 & 290,975 & 10.3 \\
\hline Physician visits & 139,992 & 5.4 & 232,573 & 6.8 & 232,573 & 7.5 & 232,573 & 8.2 \\
\hline Tests & 52,616 & & & & & & & \\
\hline Other investigation & 14,576 & & & & & & & \\
\hline Hospitalisation & 9,209 & & & & & & & \\
\hline Adverse events & 17,233 & & & & & & & \\
\hline Depression \& hypnotics & 54 & & & & & & & \\
\hline Total & $4,289,909$ & 100.0 & $3,409,571$ & 100.0 & $3,116,494$ & 100.0 & $2,823,418$ & 100.0 \\
\hline Total median cost per cure $(£)$ & 44,852 & - & 34,416 & - & 30,968 & - & 27,233 & - \\
\hline
\end{tabular}

SVR rates and therefore reduce $\mathrm{HCV}$ related morbidity and mortality [33]. The first IFN-free combinations of directly acting antivirals (DAAs) against hepatitis C $(\mathrm{HCV})$ have been licensed and more are likely to follow in the coming years. These treatments are significantly shorter in duration, yield higher SVR and have fewer AEs [34] than traditional IFN-based therapies. With expected high costs of therapy, it is important to evaluate the cost per SVR in order to maximise efficient use of scarce healthcare resources.

We set out to describe the effectiveness, safety and costs per cure for first generation protease inhibitor based treatment of genotype 1 hepatitis $C$ (the most common genotype), in a real-world UK setting.

Differences between SVR results achieved in trials (efficacy) and those in clinical practice (effectiveness) with PR $+1^{\text {st }}$ generation PIs have been previously documented [11-18]. Such differences have been attributed to the restrictive inclusion criteria of clinical trials with respect to certain groups of patients including those with advanced disease, cirrhosis and high co-morbidity burden.

While we found an overall SVR of $63 \%$ in our sample, comparable with registration trials, there was (as expected) significant variation, with cirrhotic patients and prior non-responders having worse SVR outcomes.

Just over a third $(35.7 \%)$ of patients did not complete treatment. The discontinuation rate due to treatment related $\mathrm{AE}$ amongst our sample was $11 \%$. Nearly half of patients in our sample experienced an $\mathrm{AE}$ requiring an intervention with $79 \%$ of those $\mathrm{AE}$ considered 'likely' to be treatment-related. Almost $10 \%$ of all patients required hospitalisation 'likely'- related to treatment.

Overall median total cost per cure for our sample in the base case analysis was $£ 44,852$; however, there was substantial variation among subgroups ranging from
$£ 35,492$ in treatment naive non-cirrhotics to $£ 107,288$ in cirrhotic prior non-responders. In the base case analysis for 154 patients, HCV triple therapy costs accounted for $94.6 \%$ of the total cost $(£ 4,056,229)$.

The characteristics of our UK cohort and the overall SVR rates are very similar to a study carried out in Germany, although the costs per cure estimated here were significantly lower, a difference driven to a large extent by the higher costs attributed to antivirals in Germany (see Table 6). A recent US study of similar size found a lower overall SVR rate, reflecting in part a slightly older population and a higher proportion of African-Americans, a group where a higher prevalence of IL28b T allele has been associated with poorer treatment outcomes. Despite these differences, cost per cure in the US was substantially higher, likely due to sample differences (e.g. proportion of high cost prior nonresponders 46 \% US: $22 \%$ UK) as well as differences in clinical AE management (e.g. anaemia) and drug costs).

The strength of this study is that it represents a large randomly drawn sample, representing 35 UK centres treating hepatitis $\mathrm{C}$, taken from a large UK database (HCV Research UK) and is thus likely to be representative of overall UK practice. The overall case-mix of patients considered for treatment in coming years is likely to change and the breakdown of outcomes presented according to sub-groups allows comparative analysis for different patient groups.

There are a number of factors which may underestimate the 'true' total cost per cure in our analysis. Firstly, we conducted our analysis from the direct health service perspective only, we did not consider additional indirect (such as loss in economic productivity due to treatment related side effects) or intangible costs (e.g. loss in HRQoL). Secondly, perhaps of greater impact on the definitive cost-per-cure per patient, we have not taken into 
Table 6 Comparison with recent US and German studies

\begin{tabular}{|c|c|c|c|}
\hline Patients characteristics & $\begin{array}{l}\text { Current study } \\
(n=154)\end{array}$ & $\begin{array}{l}\text { Stahmeyer et al. (GER) [35] } \\
(n=858)^{*}\end{array}$ & $\begin{array}{l}\text { Bichoupan et al. (US) [17] } \\
(n=147)\end{array}$ \\
\hline Age, years [Mean, (SD)] & $49.6(9.0)$ & $49.2(11.2)$ & $56(\mathrm{IQR}=51-61)$ \\
\hline Gender, Male [\%] & 73.4 & 58 & 68 \\
\hline \multicolumn{4}{|l|}{ Ethnicity, \% } \\
\hline Caucasian [\%] & $94.20 \%$ & $97.30 \%$ & Not reported \\
\hline Asian [\%] & $2.70 \%$ & $0.90 \%$ & Not reported \\
\hline African [\%] & $1.30 \%$ & $0.80 \%$ & $19 \%$ \\
\hline Hispanic [\%] & Not reported & $0.50 \%$ & Not reported \\
\hline Other [\%] & $1.80 \%$ & Not reported & Not reported \\
\hline \multicolumn{4}{|l|}{ SVR rate by therapy } \\
\hline BOC [\%] & 60.8 & 58.1 & Not reported \\
\hline TVR [\%] & 63.1 & 68.4 & 44 \\
\hline Cirrhosis [\%] & $21.40 \%$ & Not reported & $36 \%$ \\
\hline Prior non-responders [\%] & $22.10 \%$ & Not reported & $46 \%$ \\
\hline \multicolumn{4}{|l|}{ Cost drivers } \\
\hline Drug costs & $94.60 \%$ & $94.6-97.7 \%$ & $89 \%$ \\
\hline Pls & $68.30 \%$ & Not reported & Not reported \\
\hline TVR & Not reported & Not reported & 61 \\
\hline PegIFN & $19.50 \%$ & Not reported & $24 \%$ \\
\hline RBV & $6.80 \%$ & Not reported & $4 \%$ \\
\hline Outpatient and inpatient care (incl AEs \& follow-up) & $5.40 \%$ & $5.4-3.3 \%$ & $8 \%$ \\
\hline \multicolumn{4}{|l|}{ Cost per SVR (\$) } \\
\hline Treatment naïve & 56,576 & $73,473-82,756$ & Not reported \\
\hline Relapsers & 58,353 & $78,529-93,758$ & Not reported \\
\hline Non-responders & 125,125 & $127,1049-132,204$ & Not reported \\
\hline Overall & Not reported & Not reported & 189,000 \\
\hline
\end{tabular}

${ }^{*}$ Costs from Stahmeyer et al. were converted from euros to US dollars (conversion rate: $€ 1=\$ 1.0985$ based on European Central Bank exchange rates, March 2015)

account the additional costs of retreating the $37.7 \%$ of patients who failed PI treatment.

Analysis of cost-effectiveness is inevitably something that will change as prices of drugs, which make up the bulk of treatment costs, change. It is reasonable to expect that as there is more competition, prices will fall. Table 5 shows the effect of discount on costper-cure and given the high proportion of overall costs due to PI, discounts have a significant impact on cost-per-cure. However the results also show the proportional increase of non-discountable 'other' (largely AE management related) healthcare costs. This study provides valuable data to allow clinicians and healthcare decision makers to evaluate the real world total cost-per-cure amongst patients treated with current and future therapies. In particular, we provide a baseline dataset against which with the total cost per cure of emerging, all oral therapies can be compared and contrasted.

\section{Conclusion}

The future healthcare burden of $\mathrm{HCV}$ in the UK, as in many countries, is significant. Further prospective real world safety, effectiveness and total cost data is needed for the new IFN free treatment combinations from different healthcare settings. Comparison with this data can provide evidence to inform future treatment decisions to ensure scarce healthcare resources are able to maximize patient outcomes.

\section{Additional file}

Additional file 1: Supplementary material. (DOCX $39 \mathrm{~kb})$

\section{Abbreviations}

AE: adverse event; BOC: boceprevir; HCC: hepatocellular carcinoma; HCV: hepatitis C virus; HRG: Health Resource Group; HRQoL: health-related quality of life; IFN: interferon; NHS: National Health Service; NICE: National Institute of Health and Care Excellence; PEG: pegylated interferon; 
PI: protease inhibitor; PR: pegylated interferon and ribavirin; RBV: ribavirin; SVR: sustained viral response; TVR: telaprevir.

\section{Competing interests}

Dr Stephen Barclay: Consultant: Abbvie, BMS, Gilead, Janssen, MSD; Grants: Gilead, Janssen, MSD; Sponsored lectures: Gilead, Janssen, MSD, Roche. Dr Graham Cooke: Consultant: Janssen, Bl, Gilead and Merck; Grants: Janssen, BMS and Gilead. Miss Elizabeth Holtham: N/A. Ms Aline Gauthier: analysis funded by Gilead. Mr Jeremie Schwarzbard: analysis funded by Gilead. Mr Petar Atanasov: analysis funded by Gilead. Prof William Irving: Consultant: Merck, Novartis, BMS; Grants: Pfizer, GSK, Gilead; Educational grants: Boehringer Ingelheim, Gilead, Merck; Sponsored lectures: Janssen. None of the authors have hold any stocks or shares in an organization that may in any way gain or lose financially from the publication of this manuscript, either now or in the future.

\section{Authors' contributions}

WI contributed to study concept, design and methodology. EH developed the data collection tool and led on data collection. AG, JS, PA undertook the statistical and health-economic analysis. STB, GSC and WI lead on interpretation and appraisal of results. All authors contributed to development and critical revisions of the manuscript for important intellectual content. All authors read and approved the final manuscript.

\section{Acknowledgements}

HCV Research UK is funded by grant number C0365 from the Medica Research Foundation. GC is supported by the BRC of Imperial College NHS Trust. WI and GC are members of the STOP-HCV consortium, which is funded by the Medical Research Council.

\section{Source of funding}

This study was funded by Gilead

\section{HCV Research UK contributors}

Abouda G (Hull Royal Infirmary), Agarwal K (Kings College Hospital, London), Aldersley M (St James's University Hospital, Leeds), Alexander G (Addenbrookes Hospital, Cambridge), Aspinall R (Queen Alexandra Hospital, Portsmouth), Barclay S (Glasgow Royal Infirmary), Barnes E (John Radcliffe Hospital, Oxford), Brown A (St Mary's Hospital, London), Butterworth J (Royal Shrewsbury Hospital), Ch'ng C (Singleton Hospital, Swansea), Chadwick D (James Cook University Hospital, Middlesbrough), Cramp M (Derriford Hospital, Plymouth), Datta S (Southern General Hospital \& Glasgow Victoria Hospital), Dillon J (Ninewells Hospital, Dundee), Forton D (St George's Hospital, London), Foster G (The London Hospital), Fraser A (Aberdeen Royal Infirmary), Gelson W (Addenbrookes Hospital, Cambridge), Goldberg D (Health Protection Scotland), Gorard D (Wycombe General Hospital), Gore C (Hepatitis C Trust), Hayes P (Royal Infirmary of Edinburgh), Heydtmann M (Royal Alexandra Hospital, Glasgow), Higham A (Royal Lancaster Infirmary), Holtham E (Queen's Medical Centre, Nottingham), Hubscher S (Queen Elizabeth Hospital, Birmingham), Hutchinson S (Glasgow Caledonian University), Irving W (University of Nottingham), Jenkins N (Birmingham Heartlands Hospital), Kelly D (Birmingham Children's Hospital), Khakoo S (Southampton General Hospital), Langford A (British Liver Trust), Lawson A, (Royal Derby Hospital), Leen C (Western General Hospital, Edinburgh), McDonald S (University of Glasgow), McLauchlan J (University of Glasgow), McPherson S (Freeman Hospital, Newcastle), Mills P (Gartnavel General Hospital, Glasgow), Moreea S (Bradford Royal Infirmary), Mutimer D (Queen Elizabeth Hospital, Birmingham), Neal K (Public Health England), Patel A (University of Glasgow), Prince M (Manchester Royal Infirmary), Quinlan P (University of Nottingham), Ramsay M (Public Health England), Reddy Y (Royal Blackburn Hospital), Richardson P (Royal Liverpool University Hospital), Rosenberg W (Royal Free Hospital \& University College Hospital), Ryder S (Queen's Medical Centre, Nottingham), Shields P (Royal Preston Hospital), Shorrock C (Blackpool Victoria Hospital), Singhal S (Sandwell \& City Hospitals, Birmingham), Sreedharan A (Lincoln County Hospital), Srirajaskanthan R (University Hospital Lewisham), Stone B (Royal Hallamshire Hospital, Sheffield), Thursz M (St Mary's Hospital, London), Ustianowski, A (North Manchester General Hospital), Wilkes B (University of Nottingham), Wiselka M (Leicester Royal Infirmary).

\section{Author details}

${ }^{1}$ Walton Liver Clinic, Glasgow Royal Infirmary, Glasgow, UK. ²Division of Infectious diseases, Imperial College London, London, UK. ${ }^{3} \mathrm{NIHR}$ Nottingham Digestive Diseases Biomedical Research Unit, University of Nottingham, Nottingham, UK. ${ }^{4}$ Amaris Ltd, London, UK. ${ }^{5}$ Microbiology, Queen's Medical Centre, Nottingham NG7 2UH, UK.

\section{Received: 13 August 2015 Accepted: 16 March 2016 \\ Published online: 14 April 2016}

\section{References}

1. Messina JP, Humphreys I, Flaxman A, Brown A, Cooke GS, Pybus OG, et al. Global distribution and prevalence of hepatitis $C$ virus genotypes. Hepatology. 2015;61(1):77-87. doi:10.1002/hep.27259.

2. Eurpean Association for the Srudy of the Liver (EASL). EASL recommendations on treatment of hepatitis C 2014. J Hepatol. 2014;61(2): 373-95. doi:10.1016/j.jhep.2014.05.001.

3. EASL Recommendations on Treatment of Hepatitis C 2015. J Hepatol. 63(1): 199-236. doi:10.1016/j.jhep.2015.03.025

4. Morgan RL, Baack B, Smith BD, Yartel A, Pitasi M, Falck-Ytter Y. Eradication of hepatitis $C$ virus infection and the development of hepatocellular carcinoma: a meta-analysis of observational studies. Ann Intern Med. 2013; 158(5 Pt 1):329-37. doi:10.7326/0003-4819-158-5-201303050-00005.

5. Veldt BJ, Heathcote EJ, Wedemeyer H, Reichen J, Hofmann WP, Zeuzem S, et al. Sustained virologic response and clinical outcomes in patients with chronic hepatitis C and advanced fibrosis. Ann Intern Med. 2007;147(10): 677-84.

6. Smith-Palmer J, Cerri K, Valentine W. Achieving sustained virologic response in hepatitis C: a systematic review of the clinical, economic and quality of life benefits. BMC Infect Dis. 2015:15(1):19. doi:10.1186/s12879-015-0748-8.

7. Park C, Jiang S, Lawson KA. Efficacy and safety of telaprevir and boceprevir in patients with hepatitis C genotype 1: a meta-analysis. J Clin Pharm Ther. 2014;39(1):14-24. doi:10.1111/jcpt.12106.

8. Udina M, Castellvi P, Moreno-Espana J, Navines $R$, Valdes M, Forns $X$, et al. Interferon-induced depression in chronic hepatitis C: a systematic review and meta-analysis. J Clin Psychiatry. 2012;73(8):1128-38. doi:10.4088/JCP. $12 \mathrm{r} 07694$.

9. Gao X, Stephens JM, Carter JA, Haider S, Rustgi VK. Impact of adverse events on costs and quality of life in protease inhibitor-based combination therapy for hepatitis C. Expert Rev Pharmacoecon Outcomes Res. 2012;12(3):335-43. doi:10.1586/erp.12.10.

10. Cotler SJ, Patil R, McNutt RA, Speroff T, Banaad-Omiotek G, Ganger DR, et al. Patients' values for health states associated with hepatitis $C$ and physicians' estimates of those values. Am J Gastroenterol. 2001;96(9):2730-6. doi:10. 1111/j.1572-0241.2001.04132.x.

11. Bacon BR, Gordon SC, Lawitz E, Marcellin P, Vierling JM, Zeuzem S, et al. Boceprevir for Previously Treated Chronic HCV Genotype 1 Infection. N Engl J Med. 2011:364(13):1207-17. doi:10.1056/NEJMoa1009482.

12. Jacobson IM, McHutchison JG, Dusheiko G, Di Bisceglie AM, Reddy KR, Bzowej NH, et al. Telaprevir for Previously Untreated Chronic Hepatitis C Virus Infection. N Engl J Med. 2011;364(25):2405-16. doi:10.1056/ NEJMoa1012912.

13. Poordad F, McCone J, Bacon BR, Bruno S, Manns MP, Sulkowski MS, et al. Boceprevir for Untreated Chronic HCV Genotype 1 Infection. N Engl J Med. 2011;364(13):1195-206. doi:10.1056/NEJMoa1010494.

14. Zeuzem S, Andreone P, Pol S, Lawitz E, Diago M, Roberts S, et al. Telaprevir for Retreatment of HCV Infection. N Engl J Med. 2011;364(25):2417-28. doi: 10.1056/NEJMoa1013086

15. Ioannou GN, Beste LA, Green PK. Similar effectiveness of boceprevir and telaprevir treatment regimens for hepatitis $C$ virus infection on the basis of a nationwide study of veterans. Clin Gastroenterol Hepatol. 2014;12(8):1371-80. doi:10.1016/j.cgh.2013.12.011.

16. Price JC, Murphy RC, Shvachko VA, Pauly MP, Manos MM. Effectiveness of telaprevir and boceprevir triple therapy for patients with hepatitis $C$ virus infection in a large integrated care setting. Dig Dis Sci. 2014;59(12):3043-52. doi:10.1007/s10620-014-3294-0

17. Bichoupan K, Martel-Laferriere V, Sachs D, Ng M, Schonfeld EA, Pappas A, et al. Costs of telaprevir-based triple therapy for hepatitis C: $\$ 189,000$ per sustained virological response. Hepatology. 2014;60(4):1187-95. doi:10.1002/ hep. 27340 . 
18. Gordon SC, Muir AJ, Lim JK, Pearlman B, Argo CK, Ramani A, et al. Safety profile of boceprevir and telaprevir in chronic hepatitis C: Real world experience from HCV-TARGET. J Hepatol. 2015;62(2):286-93. doi:10.1016/j. jhep.2014.08.052.

19. Lawitz E, Mangia A, Wyles D, Rodriguez-Torres M, Hassanein T, Gordon SC, et al. Sofosbuvir for Previously Untreated Chronic Hepatitis C Infection. N Engl J Med. 2013;368(20):1878-87. doi:10.1056/NEJMoa1214853.

20. Jacobson IM, Dore GJ, Foster GR, Fried MW, Radu M, Rafalsky W, et al. Simeprevir with pegylated interferon alfa 2a plus ribavirin in treatmentnaive patients with chronic hepatitis C virus genotype 1 infection (QUEST1): a phase 3, randomised, double-blind, placebo-controlled trial. Lancet. 2014;384(9941):403-13. doi:10.1016/50140-6736(14)60494-3.

21. Manns M, Marcellin P, Poordad F, de Araujo ES, Buti M, Horsmans Y, et al. Simeprevir with pegylated interferon alfa $2 \mathrm{a}$ or $2 \mathrm{~b}$ plus ribavirin in treatment-naive patients with chronic hepatitis $C$ virus genotype 1 infection (QUEST-2): a randomised, double-blind, placebo-controlled phase 3 trial. Lancet. 2014;384(9941):414-26. doi:10.1016/s0140-6736(14)60538-9.

22. Forns X, Lawitz E, Zeuzem S, Gane E, Bronowicki JP, Andreone P, et al. Simeprevir with peginterferon and ribavirin leads to high rates of SVR in patients with HCV genotype 1 who relapsed after previous therapy: a phase 3 trial. Gastroenterology. 2014;146(7):1669-79. doi:10.1053/j.gastro.2014.02. 051. e3.

23. Pol S, Ghalib RH, Rustgi VK, Martorell C, Everson GT, Tatum HA, et al. Daclatasvir for previously untreated chronic hepatitis $C$ genotype-1 infection: a randomised, parallel-group, double-blind, placebo-controlled, dose-finding, phase 2a trial. Lancet Infect Dis. 2012;12(9):671-7. doi:10.1016/ s1473-3099(12)70138-x.

24. The price of good health. Nat Med. 2014;20(4):319-. doi:10.1038/nm.3538.

25. National Institute for Health and Care Excellence. NICE technology appraisal guidance [TA252]: Telaprevir for the treatment of genotype 1 chronic hepatitis C. 2012. https://www.nice.org.uk/guidance/ta252. Accessed 06 March 2015.

26. National Institute for Health and Care Excellence. NICE technology appraisal guidance [TA253]: Boceprevir for the treatment of genotype 1 chronic hepatitis C. 2012. https://www.nice.org.uk/quidance/ta253. Accessed 06 March 2015

27. UK HR. HCV Biobank. 2015. https://www.hcvresearchuk.org/hcv/databases. Accessed 15 April 2015.

28. British National Formulary. BNF March 2014. 2015. http://www.bnf.org/bnf/ index.htm. Accessed 28 Aug 2014

29. Department of Health. NHS Reference Costs. 2014. https://www.gov.uk/ government/collections/nhs-reference-costs. Accessed 28 Aug 2014.

30. Health \& Social Care Information Centre. Payment groupers. 2014. http:// www.hscic.gov.uk/article/3938/HRG4-201415-Payment-Grouper. Accessed 28 Aug 2014.

31. Department of Health. NHS reference costs. 2014. https://www.gov.uk/ government/collections/nhs-reference-costs. Accessed 06 March 2016.

32. Bank of England. Statistical Interactive Database - daily spot exchange rates against Sterling. 2015. http://www.bankofengland.co.uk/boeapps/ $\mathrm{iadb} /$ Rates.asp. Accessed 16 March 2015.

33. van der Meer AJ, Veldt BJ, Feld JJ, Wedemeyer H, Dufour JF, Lammert $F$, et al. Association between sustained virological response and allcause mortality among patients with chronic hepatitis $\mathrm{C}$ and advanced hepatic fibrosis. JAMA. 2012;308(24):2584-93. doi:10.1001/jama.2012. 144878.

34. Kohli A, Shaffer A, Sherman A, Kottilil S. Treatment of hepatitis C: a systematic review. JAMA. 2014;312(6):631-40. doi:10.1001/jama.2014.7085.

35. Stahmeyer JT, Rossol S, Bert F, Abdelfattah AM, Mauss S, Heyne R et al. P1147 Outcomes and costs of treating hepatitis $C$ with protein inhibitors: results from a multi-centre study. J Hepatol. 60(1):S464-S5. doi:10.1016/ s0168-8278(14)61307-6.

\section{Submit your next manuscript to BioMed Central and we will help you at every step:}

- We accept pre-submission inquiries

- Our selector tool helps you to find the most relevant journal

- We provide round the clock customer support

- Convenient online submission

- Thorough peer review

- Inclusion in PubMed and all major indexing services

- Maximum visibility for your research

Submit your manuscript at www.biomedcentral.com/submit
Biomed Central 